\title{
Evolução do Ambiente Competitivo da Indústria de Petróleo Argentina
}

\author{
Maria Alice Ferreira Deschamps Cavalcanti \\ Jorge Ferreira da Silva \\ Jorge Manoel Teixeira Carneiro
}

\section{ResUmo}

Este atigo analisa, por meio da metodologia de estudo de caso, a evolução da indústria de petróleo argentina no período de 1988 a 1996, resultante da desregulamentação iniciada em 1990, o reposicionamento estratégico da Yacimentos Petroliferos Fiscales e seu conseqüente desempenho antes e depois da privatização ocorrida em 1993. As cinco forças competitivas (Porter, 1980) evoluíram de baixas para médias, tornando o ambiente competitivo mais hostil. A Yacimentos Petroliferos Fiscales respondeu mudando de uma condição de baixa importância e/ou incoerência da maioria dos métodos competitivos (estratégia meio-termo), para uma uma nítida tendência à diferenciação (Porter, 1980). O seu desempenho evoluiu coerentemente com a sua mudança estratégica, passando de uma condição de prejuízo, expressa pelo ROA médio de -6,3\% (1988-1990), para 11,4\% (1994-1996).

Palavras-chaves: ambiente competitivo; indústria de petróleo; estratégias competitivas; desempenho; desregulamentação.

\begin{abstract}
Through the methodology of cases studies, this article analyses: the evolution of the Argentinean oil industry from 1988 to 1996 resulting basically from deregulation started in 1990; the strategic repositioning of Yacimentos Petroliferos Fiscales and its performance before and after privatization held in 1993. We show that the five competitive forces (Porter, 1980) changed from low to medium level resulting in a competitive environment more hostile. The Yacimentos Petroliferos Fiscales changed from a position of low significance and/or incoherence between the competitive methods adopted - an evidence of stuck-in-the-middle strategy - to a clear trend toward a differentiation strategy. Yacimentos Petroliferos Fiscales's performance evolved coherently with this strategic change, from a ROA loss position of $-6.3 \%$ (1988-1990), to the current value of $11.4 \%$ (1994-1996).
\end{abstract}

Key words: competitive environment; oil industry; competitive strategies; performance; deregulation. 


\section{INTRODUÇÃO}

A partir de 1990, ocorreu na Argentina o maior processo de reforma econômica até então implantado na América Latina, que levou à desregulamentação e privatização de diversos e importantes setores como o energético, o siderúrgico, o financeiro, o de comunicações e o de transporte, entre outros. Com certeza, entre os eventos mais relevantes desse programa destacam-se a desregulamentação da indústria de petróleo e a privatização, em julho de 1993, da Yacimentos Petroliferos Fiscales Sociedad del Estado (YPF) ${ }^{(1)}$ - maior empresa argentina e quarta empresa de petróleo da América Latina (atrás da PDVSA, Pemex e Petrobrás).

Esse caso é fundamental para se entender a transformação da indústria de petróleo na década atual. A YPF, uma das mais antigas empresas estatais de petróleo (criada em 1922), era o instrumento do governo para obtenção da autosuficiência em petróleo e suprimento de todo o país com derivados e, durante muitos anos, foi considerada um símbolo nacional. Se antes de 1990 a indústria de petróleo argentina era controlada pelo governo em todos os segmentos da indústria, atualmente ela é considerada a mais desregulamentada (market-driven) da América Latina e a ex-estatal vem apresentado resultados muito satisfatórios.

Os motivos para desregulamentação e privatização na indústria de petróleo podem diferir substancialmente de país para país; entretanto, em quase todos os processos, costumam ser citados alguns destes objetivos: (1) redução dos débitos nacionais; (2) atração de investimentos internacionais para a indústria; (3) aumento da competição no país; (4) melhoria da eficiência global do setor (incluindo o aumento de reservas e produção nacionais); (5) exposição das empresas à disciplina de mercado; (6) liberação dos recursos do Estado para investimentos sociais; e (7) atendimento de metas políticas de redução do papel do Estado na economia.

\section{Metodologia}

Este trabalho analisa a evolução do ambiente competitivo decorrente da desregulamentação da indústria de petróleo argentina - nos segmentos upstream e downstream, as mudanças das estratégias competitivas da YPF, e o conseqüente desempenho da empresa. $\mathrm{O}$ estudo baseou-se nos modelos desenvolvidos por 
Porter (1980), referentes às forças do ambiente competitivo e às alternativas de estratégias genéricas, e tem também o objetivo de demonstrar a adequação dessas abordagens teóricas para a análise do sucesso das empresas no contexto da indústria de petróleo, até mesmo quando ocorrem grandes mudanças devido aos processos de desregulamentação e privatização.

Para Porter (1980) o desempenho de uma empresa é função da atratividade da indústria na qual se insere e do seu posicionamento competitivo em relação aos concorrentes, resultante da implantação de suas estratégias. O primeiro aspecto as características técnicas e econômicas do ambiente externo que determinam a rentabilidade potencial que as empresas podem obter nessa indústria - pode ser analisado pelo modelo das cinco forças competitivas, enquanto o posicionamento relativo é identificado pela tipologia das estratégias genéricas.

No caso da YPF, foi comparada a estrutura da indústria e os métodos competitivos adotados pela empresa em dois períodos distintos: imediatamente antes da privatização (1988 a 1990) e após a privatização (1993 a 1996), utilizando-se diversas fontes de informações. A maior parte das conclusões, porém, está baseada nas entrevistas realizadas em julho e agosto de 1997 com vice-presidentes da empresa, gerentes de topo e alguns analistas externos (consultores dos processos de reorganização e privatização da empresa e concorrentes no mercado doméstico).

\section{Mudanças Estruturais no Segmento do Upstream}

Antes da desregulamentação, o governo exercia o monopólio das atividades do upstream, com forte controle sobre as forças que definem o ambiente competitivo. Analisando-se a estrutura da indústria nesse período, os papéis do governo e da YPF, muitas vezes, coincidem. Conforme será apresentado, a desregulamentação trouxe mudanças importantes em quase todas as forças competitivas.

Ameaça de novos entrantes. Antes de 1990, apesar de a Lei de Hidrocarburos (de 1967) permitir que o governo outorgasse licença às empresas privadas para a exploração e concessões para produção de petróleo ou gás natural, isso não era realizado por razões políticas: o petróleo era considerado um recurso estratégico do país. A única possibilidade de atuação dessas empresas era como contratistas, nome dado aos que prestavam serviço de produção de petróleo para a empresa estatal. Na verdade, terceirizava-se essa atividade, já que toda a produção das empresas privadas era entregue à YPF, por um valor prefixado, 
reajustado por fórmula contratual, sem vínculo com os preços internacionais. Em 1989 , os contratistas respondiam por cerca de $38 \%$ da produção do país. O governo tentou oferecer a atividade de exploração às empresas privadas, de contratos de risco (1978) e do Plano Houston (1985), mas as restrições de comercialização, a baixa atratividade técnico-econômica das áreas, a incerteza política desse período e, principalmente, a instabilidade econômica e a escalada inflacionária após 1986, foram motivos fortes para afastar as empresas estrangeiras, mantendo-se o monopólio da YPF.

Para permitir certo grau de competição na produção de petróleo o governo decidiu converter em concessões os antigos contratos de serviço de produção de petróleo; vender os campos menos produtivos (áreas marginais) e realizar jointventures entre empresas privadas e a YPF em quatro áreas de grande produção (associação nas denominadas áreas centrais). Assim, as empresas privadas, sobretudo as locais, adquiriram ativos significativos no upstream e, em 1992, já eram responsáveis por cerca de $56 \%$ da produção do país. Atualmente, as principais barreiras de entrada são a relativa escassez de novas áreas (novas entradas só devem ocorrer pela associação em projetos em andamento ou compra de empresas locais) e o menor preço do petróleo no mercado interno, em função da paridade com o valor de exportação.

Poder de negociação dos fornecedores. Durante a regulamentação, fornecedores locais de equipamentos e serviços tinham alto poder de barganha em relação às empresas de petróleo. Concentrados, atuavam de forma cartelizada, protegidos pelas restrições de compras internacionais de produtos com similar nacional. Tais restrições aplicavam-se a toda a indústria, mas para a estatal YPF o processo de importação de equipamentos ou insumos era mais rigoroso e lento. A abertura da economia para importações, o aumento do número de clientes e a reestruturação da função de compra da YPF influenciaram os fornecedores locais, melhorando a competitividade de seus produtos em termos de tecnologia e preço; contudo, devido à grande demanda na Argentina, o poder desses fornecedores ainda é considerado significativo pelas empresas de petróleo.

Poder de negociação dos clientes. No mercado regulamentado, os produtores de petróleo não consideravam as empresas refinadoras como seus clientes, e sim o governo, representado pela YPF. Essa visão decorria da obrigação de vender a sua produção à empresa estatal que, posteriormente, distribuía toda a produção nacional entre as refinarias. Segundo os produtores privados, seu poder de negociação dependia mais de força política e das relações com o governo do que de aspectos técnicos e econômicos. Por sua vez, os gerentes da YPF consideravam baixo o poder de negociação do cliente governo em face desses produtores. Os preços da produção nacional muitas vezes superavam os custos 
de produção da estatal e até mesmo os do mercado internacional. Hoje, na Argentina, o segmento do upstream é bem mais fragmentado ${ }^{(2)}$ que o setor de clientes de petróleo, dominado por três empresas (YPF, Shell e Esso, que possuem $84 \%$ da capacidade de refino do país). A maior concentração dos clientes e o significativo excedente da produção de petróleo em relação à demanda local tornam alto o poder de negociação dos refinadores.

Rivalidade. Como as empresas privadas só participavam da indústria prestando serviço à YPF, quase não havia concorrência no upstream. Assim, antes de 1990, a competição se dava na arena política, já que a única arma era o relacionamento com o governo. Mesmo com a desregulamentação e o estabelecimento de diversos produtores privados, a rivalidade é mediana, em função do poder de mercado da YPF (cerca de 50\% da produção do país) e da cooperação entre as empresas, sobretudo para exportar petróleo. No segundo semestre de 1996, inicia-se um processo de consolidação da indústria, por meio do incremento de fusões e aquisições que, apesar de resultar em maior nível de concentração na indústria, é percebido como tendência de aumento da rivalidade, devido à qualidade dos novos concorrentes, empresas internacionais e/ou de maior porte.

\section{Mudanças Estruturais no Segmento do Downstream}

Barreiras de entrada. Eram muito altas, antes da desregulamentação, para as atividades de refino e marketing. Além de não permitir a livre importação de petróleo ou produtos, o governo controlava a distribuição do petróleo entre as refinarias, por meio de um sistema de cotas (denominado mesa de crudos) a partir da capacidade produtiva instalada e de seus critérios para otimizar o abastecimento. A instalação de postos de gasolina também sofria restrições. Desde 1983, por exemplo, estavam suspensas autorizações para novos pontos na região metropolitana de Buenos Aires.

Em 1993, com a venda de 16\% da capacidade de refino da YPF, surgem dois refinadores: Refisan S.A. (compra da refinaria San Lorenzo) e a Refinor S.A. (compra de 70\% da refinaria de Campo Durán). Em 1994, fundem-se três pequenas empresas argentinas (Astra, Isaura e Compañia General de Combustibles), criando-se a EG3, quarta empresa na área de comercialização. Em 1996, a espanhola Repsol compra o controle da EG3. Outras empresas como a Petrobrás, Penzoil, Chevron, Elf e Texaco optaram pela entrada no nicho de mercado de lubrificantes, altamente lucrativo. Surgem ainda importadoras independentes que fornecem para grandes clientes e para postos não vinculados a 
empresas de petróleo (em 1996 esses postos eram cerca de 9\% do total). O fim das restrições legais, entretanto, não foi suficiente para aumentar significativamente o número de novas empresas no downstream, pois persistem importantes barreiras estruturais: falta de infra-estrutura portuária e de armazenagem que permita a importação rápida e expressiva de derivados de petróleo; controle das empresas estabelecidas sobre seus canais de distribuição; capacidade ociosa de refino; porte e taxa de crescimento do mercado mais baixos do que de outros países; e altos custos de transporte na importação, por conta da posição geográfica da Argentina.

Poder de negociação dos fornecedores. Durante a regulamentação, o governo era visto pelas empresas refinadoras como único fornecedor de petróleo; porém seu poder de negociação em face dessas empresas, supostamente muito alto pela condição de monopólio, era neutralizado pela influência dos compradores junto aos órgãos governamentais, sobretudo quanto ao estabelecimento de preços. Em geral, o preço do petróleo para os refinadores privados era inferior ao que a YPF pagava pelo petróleo produzido pelas empresas privadas do upstream e ao custo de produção pela YPF. Após a desregulamentação, as negociações entre as empresas produtoras do upstream e as refinadoras para compra e venda de petróleo passaram a ser diretas; contudo há maior poder relativo dos refinadores, sobretudo da Shell e da Esso, decorrente da maior concentração desse grupo e do excedente de produção de petróleo no país, que lhes permite adquirir petróleo ao preço de exportação.

Poder de negociação dos clientes. Antes de 1990, era baixa a força dos clientes industriais e postos de gasolina em relação às empresas de petróleo. Os clientes não podiam negociar os preços, fixados pelo governo, e para os postos era difícil mudar de fornecedor, pois a troca de bandeira dependia de autorização governamental. Além disso, havia restrições às importações diretas e as empresas estatais eram obrigadas a comprar produtos da YPF. Após a desregulamentação, o poder de negociação de clientes e empresas de petróleo parece mais equilibrado. Há diversidade de oferta (mais empresas refinadoras e possibilidade de livre importação) e baixo custo de mudança para os clientes (produtos semelhantes em termos de qualidade e preços). Por outro lado, observa-se que as empresas de petróleo estão conquistando parcela maior na margem de comercialização dos combustíveis.

Ameaça de produtos substitutos. A partir de 1988 tornou-se muito baixa. Antes, para privilegiar os produtores locais de álcool, havia sido introduzida na região Norte do país a alcoolnafta ( $80 \%$ de gasolina com $20 \%$ de álcool), mas que desapareceu em 1990 com o fim dos subsídios. Em meados da década de 70, a substituição de derivados de petróleo por gás natural foi explicitamente favorecida pelo governo com a manutenção de preços baixos. Por isso, em 1990, o 
consumo de gás natural já representava cerca de $44 \%$ do consumo energético do país, limitando bastante substituições adicionais.

Rivalidade. Considerada muito baixa antes da desregulamentação, pois as principais armas competitivas eram controladas pelo governo. Os preços dos produtos eram fixados e iguais em todo o país; a instalação de postos de gasolina dependia de autorização da Secretaria de Energia; as estatais eram obrigadas a comprar da YPF; proibia-se a construção de novas refinarias; as ampliações das existentes dependia de autorização, assim como as importações de derivados. Com o market-share predeterminado pela cota de petróleo a processar e pelo número e localização dos postos, ambos definidos pelo governo, restavam, para as empresas, poucas possibilidades de aumentá-lo. A partir da desregulamentação, em 1991, a concorrência intensificou-se com o uso de armas competitivas relativas à imagem, à qualidade dos produtos, ao nível de serviços e à sofisticação e localização dos postos de gasolina; contudo o alto grau de concentração na indústria (quatro grandes empresas - YPF, Shell, Esso e EG3 dominam 93\% do mercado de gasolina e diesel) vem permitindo um comportamento oligolopolizado em relação à maioria dos preços.

Tabela 1: Análise da Estrutura da Indústria de Petróleo Argentina

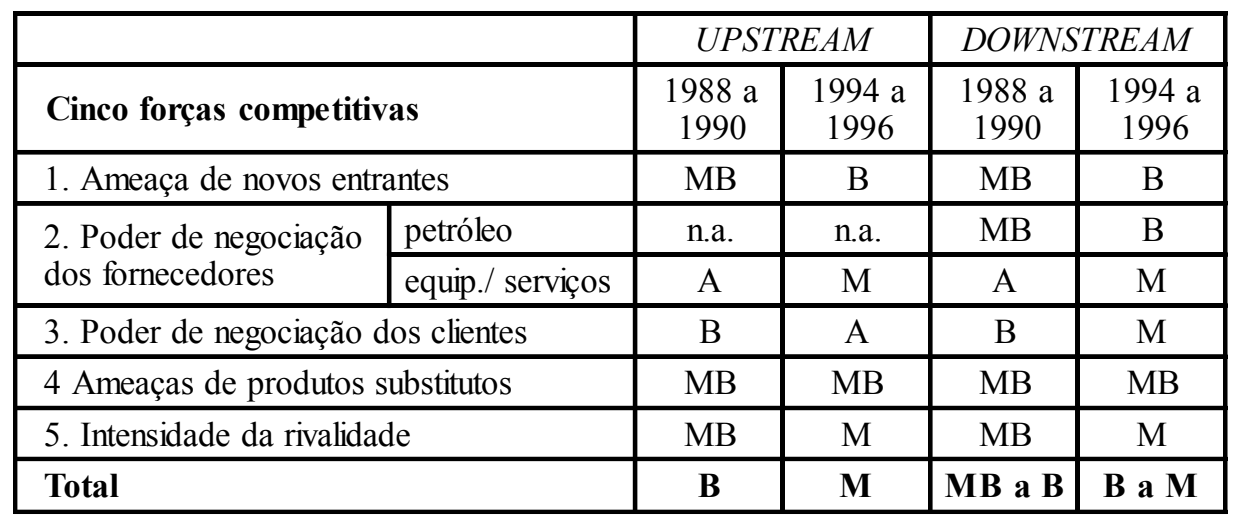

Legenda: intensidade das forças:

A: alta;

M: média;

B: baixa;

MB: muito baixa;

n.a: não aplicável.

Fonte: Cavalcanti (1997). 


\section{Evolução da Estratégia Competitiva}

A YPF respondeu à mudança do ambiente competitivo anteriormente descrita com significativo reposicionamento estratégico. Nesta pesquisa tal mudança foi avaliada em função da ênfase dada pela gerência da empresa a diversas variáveis estratégicas ${ }^{(3)}$, sempre em relação ao posicionamento dos concorrentes na Argentina. A seguir serão discutidas as mudanças observadas na YPF, comparando-se as situações anteriores e posteriores à sua transformação e privatização.

Amplitude da linha de produtos e da carteira de clientes. Aparentemente, na regulamentação, havia restrições do governo quanto à atuação da YPF em alguns segmentos de mercado, como o varejo do GLP e a petroquímica. Por outro lado, sua carteira de clientes era mais ampla (as outras empresas estatais eram clientes cativos, ainda que inadimplentes muitas vezes). Com a desregulamentação, a YPF diversificou seus produtos, com a compra de participação em diversas petroquímicas, aquisição, em 1993, da empresa distribuidora de GLP da AGIP (atual YPF Gas S.A.), além de que houve a inclusão de lubrificantes especiais.

Foco na segmentação do mercado e importância dos nichos de mercado. No mercado regulamentado a YPF não fazia distinção de atendimento, preço ou qualidade dos produtos entre os diferentes clientes e nem priorizava os segmentos-alvos. Enquanto isso, a Shell focava os segmentos de gasolina de alta qualidade e lubrificantes automotivos e a Esso priorizava o mercado de diesel agrícola. Hoje, a estratégia de segmentação da empresa é similar à dos concorrentes. Quanto aos lubrificantes, talvez pela grande perda de mercado (de 55\% em 1988 para 35\% em 1995), em 1995, foi criada uma unidade de negócio específica, independente das outras divisões do downstream, visando a aumentar a competitividade nesse segmento.

Lançamento de produtos. Ainda que as quatro maiores empresas procurem equiparação em termos de qualidade, a YPF mudou radicalmente com a desregulamentação, buscando pioneirismo nos lançamentos para o mercado argentino, como ocorreu com a gasolina sem chumbo, o diesel de qualidade superior em termos de cetano e o lubrificante de qualidade SJ.

Nível de serviços. Por sua experiência internacional, os principais concorrentes sempre demonstraram preocupação maior que a YPF com os serviços oferecidos nos postos de gasolina e aos clientes industriais; mas, a partir de 1993, a YPF considera que vem enfatizando, mais do que a concorrência, a oferta de serviços em sua rede de postos e, em função dos laboratórios especializados, tem se distinguido na assistência técnica aos clientes industriais. 
Qualidade dos produtos. Segundo a opinião dos clientes, a YPF tem evoluído muito. Seus produtos já foram considerados os piores do país, mas já em 1996, a gasolina e os lubrificantes eram considerados similares à média do mercado (os da Shell ainda eram reconhecidos como superiores) e o diesel reconhecido nos mercados urbanos como de qualidade superior. Para isso, a YPF realizou grande esforço para melhorar a qualidade intrínseca dos produtos, investindo em unidades produtoras e controlando melhor a distribuição dos produtos.

Preço. Mesmo com a liberação dos preços, de 1991 a 1993, para minimizar a perda de market-share a YPF manteve o menor preço do mercado. Essa escolha devia-se à péssima imagem da YPF em termos de qualidade - dos produtos, do atendimento e dos postos de gasolina - e também porque a maioria de seus recursos estavam empenhados nos processos de venda de ativos e reestruturação organizacional. Após essa transição, a YPF altera sua política e hoje, para a maioria dos produtos, é a segunda empresa em termos de $\operatorname{preços}^{(4)}$. Buscando rentabilidade, e não volume de venda, a YPF passa a praticar preços mais elevados; porém, como líder ( $46 \%$ de market-share), é formadora de preços no mercado argentino e, portanto, o seu procedimento nessa questão tende a ser muito criterioso.

Propaganda e promoção, imagem da empresa. Antes da desregulamentação, a publicidade da YPF era esporádica e com orientação institucional, pois as estatais eram proibidas de fazer propaganda de produtos. Atualmente, a intensidade da propaganda e promoção da empresa é equivalente à da concorrência e, para a YPF, a imagem dos postos de gasolina é o fator mais importante da sua estratégia de venda no varejo. Em 1993, a empresa francesa SOPHA desenvolveu o projeto Nueva Imagen para os postos de gasolina da YPF, intensificando o programa de modernização da sua rede, iniciado um ano antes. Para os gerentes da YPF, o projeto, ainda que mais caro que os da concorrência, está no nível dos melhores designs do mundo. Até 1996, a YPF modernizara cerca de $85 \%$ da sua rede, com $11 \%$ dos postos convertidos à Nueva Imagen.

Controle sobre os canais de distribuição. Enquanto os concorrentes controlavam com rigor os postos de gasolina e os distribuidores (atacado), a YPF dava pouca importância a esse aspecto; por isso tinha problemas de adulteração dos produtos nos postos operados por terceiros, além de receber produtos que tinham sido entregues aos distribuidores, faturados no preço inferior de atacado. Fora isso, muitos distribuidores da YPF não eram leais e vendiam também produtos da concorrência. Após a desregulamentação, mesmo melhorando significativamente, a YPF continua tendo menor grau de controle sobre os postos de gasolina, devido ao menor número de postos próprios (cerca de 3\%, em 1996, enquanto a média da concorrência é de $20 \%$ ) e à terceirização de parte das vendas para os postos YPF, nas áreas dos concessionários zonais ${ }^{(5)}$. 
Vendas diretas. No período do mercado regulamentado, a maioria das vendas diretas era compulsória (para outras empresas estatais). O restante era vendido por um grande número de distribuidores, tornando a YPF altamente dependente dos canais de distribuição. Após 1993, mesmo com a maior preocupação da YPF com as vendas diretas, visando ao maior conhecimento de seus clientes, avalia-se que a ênfase dada pela concorrência a esse método competitivo ainda seja maior.

Controle de custos. A ênfase da YPF no controle dos custos de produção (upstream e downstream) alterou-se significativamente, permitindo que, em 1996, os custos de refino estivessem equivalentes aos dos outros refinadores argentinos. Durante a regulamentação, a empresa privilegiava metas volumétricas de produção ao invés de custos, enquanto seus concorrentes no downstream, provavelmente, consideravam o controle de custos um dos principais métodos competitivos disponíveis, já que os preços e cotas de produção eram controlados pelo governo.

Utilização da capacidade produtiva. Apesar da YPF ter mantido, no período de 1988 a 1996, o nível de utilização da capacidade produtiva em torno de 75\% (exceto em 1995, quando foi de 69\%, devido à recessão econômica), antes de 1990, com a obrigação de atender à demanda de derivados de petróleo, esse nível era mais alto que a média da concorrência (55\%). Depois, por conta da expressiva perda de mercado, avalia-se que a capacidade ociosa de suas refinarias seja superior a da concorrência. Durante a regulamentação, essa condição não conferia vantagem de custo para a YPF, pois existiam outros fatores contrários, como o alto custo da mão-de-obra e a baixa eficiência operacional.

Eficiência operacional. Em 1994, para recuperar o baixo nível de eficiência de suas refinarias, a YPF assinou com a Chevron um acordo de assistência técnica para a refinaria de La Plata, visando, principalmente, a reduzir o consumo energético e as perdas de produtos e a melhorar os processos de gestão. Hoje, a YPF considera que suas refinarias apresentam eficiência operacional superior a dos outros refinadores argentinos.

Aquisição da matéria-prima (downstream). No período de 1993 a 1996, apenas a YPF, EG3 e Pérez Companc processavam em suas refinarias petróleo próprio, enquanto os outros refinadores (Shell e Esso) compravam de produtores independentes ou importavam, provavelmente, com alguma desvantagem de custo.

Grau de inovação dos processos produtivos e de modernização das instalações. A atualização tecnológica de suas refinarias sempre foi prioridade para a YPF mas, antes da desregulamentação, essa preocupação decorria de metas técnicas ou de políticas do governo e não das exigências do mercado. Em 1996, a YPF considerava estar realizando um esforço superior ao da concorrência em termos de automação de refinarias e terminais. Também apresentava um grau de 
conversão no refino muito superior e, em função dos investimentos em novas unidades de booster de octanagem, realizados após a privatização, havia alcançado a média da concorrência na Argentina.

Intensidade e objetivo dos investimentos. Os investimentos da YPF em instalações produtivas sempre foram maiores que os da concorrência; contudo, até 1988, os objetivos eram aumentar a produção e adequar as refinarias ao planejamento energético do governo, como no caso dos investimentos, na década de 80, de aumento de capacidade de conversão nas refinarias de La Plata e Luján de Cuyo (cerca de US\$800 milhões financiados pelo Banco Mundial). Com a privatização, seus investimentos visam à qualidade dos produtos (principalmente da gasolina), à adequação da estrutura de custos produtivos e à modernização e ao aumento do controle sobre a rede de postos de gasolina.

Pesquisa e desenvolvimento. Durante a regulamentação, o exclusivo Centro de Pesquisa da YPF não representava vantagem competitiva, pois as pesquisas não se vinculavam às necessidades operacionais e de marketing da empresa e os projetos desenvolvidos eram relacionados a tecnologias maduras e disponíveis. Consciente da baixa eficiência e eficácia da pesquisa e desenvolvimento (P\&D), a YPF optou por fechar o Centro de Pesquisa e criar pequenos centros de tecnologia aplicada para cada área de negócio (upstream e downstream), que visam a otimizar os processos existentes, dar assistência técnica e desenvolver produtos a partir da consultoria de fornecedores internacionais. Atualmente, a YPF busca a liderança tecnológica na Argentina (entendida como vanguarda na qualidade dos produtos), mas sem desenvolvimento tecnológico próprio, por considerar que quase todas as tecnologias necessárias podem ser facilmente adquiridas no mercado internacional.

Qualificação e motivação dos empregados. Antes da desregulamentação, o quadro técnico da YPF era superior ao da concorrência, mas os gerentes, em geral, não apresentavam qualificação em gestão empresarial. Com a reestruturação organizacional, a YPF procurou contratar profissionais com alta qualificação gerencial e experiência internacional, e incentivou o treinamento gerencial em universidades americanas. A condição de estatal diminuía a motivação de muitos empregados, principalmente pelas questões salariais, pela frustração devido ao baixo poder decisório e pela falta de perspectivas atraentes. Hoje, a maioria acredita que a YPF valorize a motivação dos empregados, porque, além de os salários, em geral, estarem acima da média da indústria de petróleo local, contribui a maior descentralização das decisões e a sensação de construir uma nova empresa.

Estratégias de crescimento. Como estatal, os objetivos de crescimento da YPF estavam associados a parâmetros volumétricos: auto-suficiência do país em 
petróleo, substituição das importações de derivados e abastecimento de produtos no mercado, independentemente da rentabilidade. Após a desregulamentação, a empresa vem adotando diversas estratégias para aumentar suas receitas, como modernização dos postos de gasolina; oferta de produtos de alta qualidade e serviços superiores; aumento da utilização da capacidade produtiva; ampliação da atuação na América Latina, buscando mercados atrativos (por exemplo, revenda no Chile) e/ou oportunidades decorrentes de desregulamentação (por exemplo, Peru e Brasil); internacionalização no upstream e maior participação nos mercados de gás natural e petroquímicos.

\section{Estratégia Genérica Adotada pela YPF}

A síntese do posicionamento da YPF nas diversas variáveis estratégicas está apresentada na Tabela 2, a partir da qual, em conjunto com os critérios de classificação anteriormente pré-definidos (Cavalcanti, 1997), foi possível inferir a estratégia competitiva genérica da YPF, segundo a tipologia de Porter $(1980,1985)$.

Antes da desregulamentação, apesar de a YPF enfatizar alguns métodos competitivos, a sua principal característica era a baixa importância atribuída à maioria das variáveis estratégicas. Em síntese, em comparação aos seus principais concorrentes, a YPF não enfatizava: o lançamento de novos produtos; o nível dos serviços; a qualidade dos produtos; a propaganda e promoção; a identidade de marca e imagem da empresa; o controle sobre os canais de distribuição; as estratégias de segmentação; o controle de custos e a eficiência operacional. Além disso, pode-se dizer que o posicionamento da YPF, na maioria das variáveis estratégicas, era resposta às determinações governamentais, sem traduzir uma escolha da empresa ou resultar em real vantagem competitiva; portanto, nesse período, a YPF foi classificada como meio-termo, em conseqüência da incoerência entre as poucas variáveis estratégicas enfatizadas e da ausência dos principais métodos competitivos.

No período de 1994 a 1996, a YPF apresentava uma tendência à diferenciação, porquanto, em comparação aos concorrentes na Argentina, dava maior importância à maioria dos métodos relacionados a esse tipo estratégico; contudo outros métodos competitivos, mais ligados a custos, também vêm sendo enfatizados pela YPF, talvez em decorrência do seu processo de transformação, extremamente rigoroso mas necessário, no aspecto dos custos, para recuperar-se de uma condição muito desfavorável. 
Tabela 2: Síntese da Avaliação das Variáveis Estratégicas da YPF

\begin{tabular}{|l|c|c|}
\hline Variável estratégica & $\mathbf{1 9 8 8}$ a 1990 & $\mathbf{1 9 9 3}$ a 1996 \\
\hline 1. amplitude da linha de produtos & (M-) & A \\
\hline 2. amplitude e diversidade da carteira de clientes & (A) & A \\
\hline 3. estratégia de segmentação & B- & M \\
\hline 4. nichos de mercado & B- & M \\
\hline 5. lançamento de novos produtos & (B) & A \\
\hline 6. nível de serviços & B- & A \\
\hline 7. qualidade dos produtos & B & A (percebida \\
& como M) \\
\hline 8. política de preços & $\begin{array}{c}\text { (fixados pelo } \\
\text { governo) }\end{array}$ & M+ \\
\hline 9. intensidade de propaganda e promoção & (B-) & M \\
\hline 10. identidade da marca e imagem da empresa & B- & A \\
\hline 11. controle sobre os canais de distribuição & B- & B \\
\hline 12. vendas diretas & B & B \\
\hline 13. controle de custos & B- & A \\
\hline 14. utilização da capacidade produtiva & (A) & B \\
\hline 15. eficiência operacional & B & A \\
\hline 16. aquisição de matéria-prima & M & A+ \\
\hline 17. grau de inovação dos processos produtivos e \\
de modernizção das instalações & A & A \\
\hline 18. intensidade dos investimentos & (A) & A \\
\hline 19. objetivo dos investimentos & $\begin{array}{c}\text { aumento } \\
\text { capacidade de } \\
\text { produção }\end{array}$ & $\begin{array}{c}\text { qualidade, } \\
\text { imagem, custos }\end{array}$ \\
\hline 20. importância da P\&D & (A) & A \\
\hline 21. liderança tecnológica & $\begin{array}{c}\text { A (técnicos); } \\
\text { B (gerentes) }\end{array}$ & A \\
\hline 22. qualificação da mão-de-obra & B- & A \\
\hline 23. motivação dos empregados & inexistente & qualidade, \\
imagem, \\
24. estratégias de crescimento & & $\begin{array}{c}\text { diversificação } \\
\text { de negócios }\end{array}$ \\
\hline
\end{tabular}

Legenda:

B-: ênfase (ou nível) muito menor que a concorrência;

B: menor ênfase (ou nível) que a concorrência;

M-: ênfase (ou nível) ligeiramente inferior à concorrência;

$\mathrm{M}$ : ênfase (ou nível) equivalente à concorrência;

$\mathrm{M}+$ : ênfase (ou nível) ligeiramente superior à concorrência;

A: ênfase (ou nível) maior que a concorrência;

$\mathrm{A}+$ : ênfase (ou nível) muito maior que a concorrência.

( ): indica que o posicionamento da YPF era decorrente de imposição governamental e/ou não representava uma fonte de vantagem competitiva, sendo considerado com ressalvas para efeito de classificação da estratégia genérica. 


\section{Evolução do DESEMPENHo dA YPF}

Como esperado, devido à boa atratividade da indústria de petróleo argentina, à adoção de uma estratégia de diferenciação bem definida, além da provável melhoria dos processos organizacionais obtida com os ajustes prévios para a privatização, a YPF apresentou uma significativa melhora na sua rentabilidade, em termos de retorno sobre os ativos - ROA (calculado com o lucro operacional). Em termos globais, a empresa passou de uma situação de prejuízo, expressa pelo ROA médio de $-6,3 \%$ no período de 1988 a 1990, para outra de alta lucratividade, obtendo em média 11,4\% de ROA (1994-1996). A rentabilidade da YPF nesse segundo período foi equivalente à média de outras empresas de petróleo internacionais.

Antes da desregulamentação, como a YPF buscava principalmente a auto-suficiência do país em petróleo, no período de 1988 a 1990 sua produção própria ficou praticamente constante: cerca de 339.000 bpd. De 1991 a 1993, a produção caiu cerca de $32 \%$, sobretudo por conta das determinações governamentais de venda de campos de produção. No período pós-privatização, a YPF mostrou crescimento constante da produção de petróleo, alcançando 414.000 bpd em 1996.

Já no downstream, a YPF reduziu a participação no mercado. No início da desregulamentação, são fatores importantes para explicar tal fenômeno, a venda de $16 \%$ da capacidade de refino da YPF, por determinação do governo, para aumentar rapidamente a concorrência; a baixa qualidade de produtos e serviços dos postos da YPF; o controle deficiente da rede de postos; a perda de clientes para a concorrência, além da inexperiência em mercados competitivos. Depois, a participação de mercado resulta, basicamente, do novo posicionamento estratégico da YPF de maximização da rentabilidade, ao invés do volume de vendas.

Tabela 3: Evolução da Participação de Mercado da YPF

\begin{tabular}{|l|c|c|c|c|}
\hline \multicolumn{1}{|c|}{ Produto } & $\mathbf{1 9 8 8} / \mathbf{1 9 9 0}$ & $\mathbf{1 9 9 1 / 1 9 9 3}$ & $\mathbf{1 9 9 4 / 1 9 9 6}$ & $\begin{array}{c}\text { perda de } \\
\text { mercado }\end{array}$ \\
\hline Gasolina (comum + especial) & $55,1 \%$ & $53,0 \%$ & $45,8 \%$ & $\mathbf{- 9 \%}$ \\
\hline Diesel & $61,4 \%$ & $56,5 \%$ & $44,2 \%$ & $\mathbf{- 1 7 \%}$ \\
\hline Lubrificantes & $53,2 \%$ & $44,2 \%$ & $38,1 \%$ & $\mathbf{- 1 5 \%}$ \\
\hline QAV & $75,9 \%$ & $58,9 \%$ & $53,0 \%$ & $\mathbf{- 2 3 \%}$ \\
\hline GLP & $77,2 \%$ & $47,0 \%$ & $53,7 \%$ & $\mathbf{- 2 3 \%}$ \\
\hline Óleo combustível & $83,7 \%$ & $65,7 \%$ & $12,4 \%$ & $\mathbf{- 7 1 \%}$ \\
\hline
\end{tabular}

Fonte: Cavalcanti (1997). 
Em função do indicador enfatizado, rentabilidade ou participação de mercado, pode-se concluir que o desempenho da YPF tenha ficado melhor ou pior; porém, essa aparente contradição apenas revela a opção da estratégia de diferenciação, que busca o aumento das margens por meio de métodos competitivos menos dependentes de aumento do volume de vendas (vide Figura 1).

Outro significativo sinal de melhoria do desempenho é dado pelo índice de satisfação dos stakeholders (governo, acionistas, clientes, empregados, sociedade). Em todos os casos, quando comparados aos concorrentes na Argentina, passaram de uma posição de insatisfação para outra de maior satisfação com a YPF.

\section{Figura 1: Rentabilidade da YPF versus Participação no Mercado de Gasolina e Diesel}

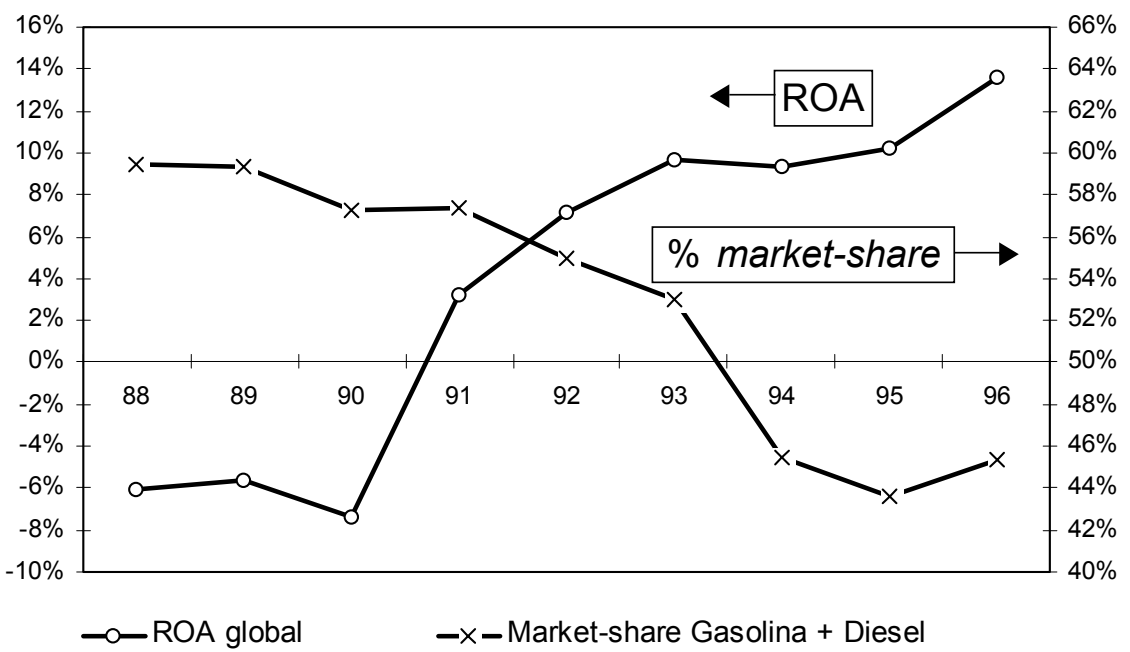

Fonte: Cavalcanti (1997).

\section{Conclusão}

A desregulamentação alterou o ambiente competitivo para as atividades do upstream e do downstream na Argentina, levando ao reposicionamento estratégico quase todas as empresas de petróleo, em particular a YPF. Eliminadas as restrições e interferências do governo, criou-se um ambiente competitivo mais hostil para todos, pois as cinco forças competitivas, em conjunto, evoluíram de um nível baixo para médio. Assim, conforme postulado por Porter $(1980,1985)$, pode-se supor que, a partir de 1990, a atratividade da indústria de petróleo argentina diminuiu em relação ao período de mercado regulado; mas, como o nível das 
forças competitivas ainda é favorável, com estratégias bem definidas, as empresas de petróleo estabelecidas tendem a um bom desempenho.

No caso argentino, o reposicionamento da empresa estatal com a desregulamentação da indústria, mostra a criação de diversas oportunidades como estas: priorização de objetivos econômicos em relação aos de volume de produção; racionalização de ativos e concentração em negócios mais rentáveis; redução de custos; redefinição de processos organizacionais; desenvolvimento de novas capacitações; foco nas necessidades dos clientes; liberdade de escolha de métodos competitivos; realização de negócios em parceria e internacionalização. Por tudo o que foi visto, é lícito considerar que a YPF soube aproveitar várias dessas oportunidades e, também, que o processo de desregulamentação da indústria de petróleo não é, necessariamente, maléfico para as empresas estatais, ex-executoras do monopólio, quando se garante a equivalência de condições competitivas ${ }^{(6)}$.

\section{NOTAS}

${ }^{1}$ O programa de privatizações argentinas no período de 1990 a 1996 resultou em cerca de US\$24 bilhões, o que correspondeu a cerca de $30 \%$ do PIB gerado neste período. A privatização da YPF (venda de ativos e da participação acionária) equivale a $22 \%$ deste montante.

${ }^{2}$ De acordo com o Instituto Argentino de Petróleo e Gás Natural (IAPG), em 1996, a YPF era proprietária de $48 \%$ das reservas de petróleo do país, 8 empresas controlavam $32 \%$ e os $20 \%$ restantes das reservas de petróleo estavam distribuídos entre 87 empresas menores.

${ }^{3}$ Na pesquisa foram analisadas 41 variáveis; contudo neste artigo serão apresentadas apenas as mais relevantes para classificação do tipo de estratégia genérica e/ou que sofreram grande mudança.

${ }^{4}$ Em relação à gasolina, a YPF procura manter seu preço um pouco inferior ao da Shell, que pratica sempre os maiores preços; no diesel atua com os preços médios da indústria e nos lubrificantes automotivos tem buscado os preços mais baixos do mercado. Para os clientes industriais a YPF não privilegia o preço como método competitivo, e sim a oferta do melhor mix de qualidade, serviço e preço.

${ }^{5}$ Apenas a YPF possui a modalidade de distribuição concessionários zonais, firmas que administram as vendas para os postos de gasolina operados por terceiros, restritos a certa área geográfica, recebendo comissão por volume de vendas e pelos investimentos realizados.

${ }^{6}$ o artigo apresenta, exclusivamente, a opinião particular dos autores e não o posicionamento da Petrobrás ou da YPF. 
Bibliografia

ALBARRACIN, S. F.;

DOW, S. R.

Privatisation of the Argentine state-owned oil company. Journal of Energy and Natural Resources Law, v. 13, n. 2, p. 108-119, 1995.

\section{ALEGRETTA, A.}

Por qué una organización independiente para la División Lubricantes da YPF? Palestra apresentada pelo Vice-Presidente no Seminário de Lubrificantes da Petrobrás. [S.1.], jun. 1997.

\section{ARTHUR D. LITTLE DE} ARGENTINA S.A.

Transforming YPF : the Arhur D. Little experience. Buenos Aires, mar. 1996. reprodução da apresentação ao governo boliviano realizada em abr. 1994.

AUSTIN, J. E.

Managing in developing countries : strategic analysis and operating techniques. New York: Free Press, 1990.

BRIDGER, C.

YPF - el nuevo marco regulatorio de gas y petroleo. Palestra apresentada pelo Vice-Presidente de Finanças no Congresso da ARPEL. Rio de Janeiro, out. 1996.
CALGANO Y ASOCIADOS S. A. The Argentine oil and gas industry. 2/4. eds. Buenos Aires: [s.n.], 1996. v. 1.

CARNEIRO, J. M. T.

Alterações nas estratégias competitivas decorrentes de desregulamentação e de privatizações na indústria do petróleo : um estudo de casos. Rio de Janeiro, 1997. Dissertação (Mestrado em Administração) Departamento de Administração, Pontifícia Universidade Católica do Rio de Janeiro.

CARNEIRO, J. M. T.;

CAVALCANTI, M. A. F. D.;

SILVA, J. F.

Porter revisitado : análise crítica da tipologia estratégica do mestre. In: XXI ENCONTRO ANUAL DA ANPAD (1997 : Angra dos Reis). Anais Eletrônicos... Rio de Janeiro : ANPAD, 1997.

CAVALCANTI, M. A. F. D.

Impactos organizacionais decorrentes da desregulamentação do setor petrolífero argentino: estudo de caso da Yacimentos Petrolíferos Fiscales - YPF. Rio de Janeiro, 1997. Dissertação (Mestrado em Administração) - Departamento de Administração, Pontifícia UniversidadeCatólicado Riode Janeiro. 
ENERFINANCE DOWNSTREAM SERVICES \& THE PETROLEUM FINANCE COMPANY LTD.

Refining and marketing in Latin America - Argentina. [S.1.], 1996a.

Oil company competitor analysis - Yacimientos Petrolíferos Fiscales Sociedad Anónima. [S.1.], 1996b.

INSTITUTO ARGENTINO DEL PETROLEO Y DEL GAS.

Reservas de petróleo y gas. Buenos Aires, Secretaria de Energia y Puertos, Subsecretaria de Combustibles, 1996.

INSTITUTO DE ECONOMIA ENERGETICA - FUNDACIÓN BARILOCHE.

Estudio sobre el mercado petrolero en Argentina. Buenos Aires, abr.-mayo-jun. 1996. relatório interno da Petrobrás. $1^{\mathrm{a}}$ parte. cap. $6,7,8,9.2^{\mathrm{a}}$ parte. cap. 2 , $3,5.3^{\text {a }}$ parte. cap. 2,3 .

KNOOP, C. I.

YPF Sociedad Anónima (A, B, B-1 e B-2). Boston, Harvard Business School, Sept. 1995. cases.

KOZULJ, R.;

BRAVO, V.

La politica de desregulacion petrolera argentina - antece- dentes e impactos. Buenos Aires: Instituto de Economia Energética/ Fundación Bariloche, 1993.

MILES, R. E. et al.

Organizational strategy, structure, and process. Academy of Management Review, v. 3, n. 3, p. 546-562, July 1978.

OIL \& GAS JOURNAL.

Argentina pushes to court foreign operators (Part II). [S.1.: s.n.], v. 89, n. 2, p. 51-53, Jan. 1991a.

Argentina's YPF homes in on privatization. [S.1.: s.n.], v. 89, n. 39, p. 26-28, Sept. 1991 b.

YPF refineries aiming for world class operations. [S.1. : s.n.], v. 93 , n. 7, p. 54-57, Feb. 1995a. OGJ Special.

Argentina spells out upstream, downstream plans. [S.1. : s.n.], v. 93, n. 12, p. 121-122, Mar. 1995b.

PALADINO, M.

Sector petrolero argentino el proceso de desregulación. Buenos Aires, Universidad Austral, Instituto de Altos Estudios Empresariales - IAE, mayo 1990. documento. 
PALADINO, M.;

DAMBRA, L.

\section{Yacimentos Petrolíferos}

Fiscales - YPF (A). Buenos Aires, Universidad Austral, Instituto de Altos Estudios Empresariales - IAE, ene. 1991a. rev. 2. caso P-1-18.

\section{Yacimentos Petrolíferos}

Fiscales - YPF (B). Buenos Aires, Universidad Austral, Instituto de Altos Estudios Empresariales-IAE, ene. 1991b. rev. 2. caso p.1-19.

PETROLEUM ECONOMIST; ARTHUR ANDERSEN.

The guide to world energy privatisation. London, Mar. 1995.

PORTER, M. E.

Competitive strategy: techniques for analysing industries and competitors. New York : Free Press, 1980.

Competitive advantage : creating and sustaining competitive performance. New York : Free Press, 1985.

ROSS, C. E.

Recreating the Argentine national oil company : a paradigm for privatization. Prism, p. 31-47, $2^{\text {nd }}$ Quarter 1994.

TREAT, J. E. et. al.

Creating the high performance international petroleum company : dinosaurs can fly. Tulsa : Penn Well, 1994.

UBS GLOBAL RESEARCH, OIL \& GAS HANDBOOK.

Company profiles and forecasts, oil \& gas team. London : [s.n.], v. 1/ 2, Nov. 1995.

YACIMENTOS PETROLIFEROS FISCALES SOCIEDAD DEL ESTADO.

Balance general 'resumido' 1988/1989. [S.1., 198-].

Memoria y balance general ejercicio n. 14 de 1990. [S.1.], dic. 1992.

Prospectus. [S.1.], CS First Boston Group \& Merrill Lynch Co., June 1993a.

Annual report. [S.1.], 1993b.

Annual report. [S.1.], 1994.

Annual report. [S.1.], 1995.

Annual report. [S.1.], 1996a.

Palestra apresentada aos investidores internacionais, Road Show. [S.1.], dez. 1996b.

Apresentação interna sobre os resultados de 1995, 1996 e 1997 da SBU Downstream. [S.1.], jun. 1997. 